\title{
INFLUENCE DU MODE DE DISTRIBUTION DES MATIÈRES AZOTÉES DU RÉGIME SUR L'EFFICACITÉ ET LE COMPORTEMENT ALIMENTAIRE DU POUSSIN
}

\author{
C. CALET et A. ALBESSARD \\ Station de Recherches avicoles, \\ Centre national de Recherches zootechniques, Jouy-en-Josas (Seine-et-Oise)
}

\section{SOMIMAIRE}

On distribue la ration du poussin en deux repas indépendants. L'un, de nature protidique, présente un taux variable de matières azotées ( $5 \circ$ et $30 \mathrm{p}$. тoo). L'autre est constitué d'aliments non azotés qui sont offerts à volonté. Les protides étudiés ont des valeurs biologiques très différentes, farine de poisson dans un cas, tourteau d'arachide et gluten de maïs dans l'autre. Dans tous les cas les animaux reçoivent la même quantité journalière d'azote.

Lorsque le poussin reçoit de la farine de poisson, le taux protidique du repas azoté n'a aucune influence sur le gain de poids corporel. Il n'en est pas de même lorsque l'on s'adresse au mélange arachide-gluten pour lequel le taux protidique le plus faible permet la croissance la plus élevée.

En revanche, pour chacune des deux sources azotées, l'influence du taux protidique ne se manifeste plus lorsque l'on considère le taux de conversion alimentaire ou l'efficacité de l'énergie du régime. Pour des protides donnés, il existe une relation très étroite entre le gain de poids et la consommation spontanée d'énergie qui n'est absolument pas modifiée par le mode de distribution des ma. tières azotées.

Ainsi la présence de substances ternaires aux côtés des matières azotées (régime à $30 \mathrm{p}$. I00 de matières azotées totales) ne modifie jamais l'efficacité de l'ensemble de l'aliment mais retentit parfois sur l'appétit de l'animal.

\section{IN'TRODUC'TION}

Depuis longtemps les chercheurs proposent des méthodes biologiques d'appréciation de la qualité des aliments et en particulier de leur efficacité protidique. La plus vieille en date est, chez le poussin, celle de Heiman et al. (I939) dénommée "Gross Protein Value " ou Valeur Brute des Protides et reprise plus récemment par Anwar, (I962). La signification des résultats de chacune des méthodes dépend des conditions nutritionnelles de leur application : BARNes et BOSSHARDT (I946) attirent 1'attention sur l'importance du taux protidique du régime : Combs (I959) ; LEONG et al. (I959); Hohls (I958) et GuIL,AUME, (I96I) mettent en lumière le rôle du taux énergétique et du rapport Calorie/Matière azotée. 
Il ressort de ces études que pour être valable, la mesure de l'efficacité protidique requiert la distribution en quantité constante et par conséquent limitée de l'aliment azoté. Elle ne doit cependant pas être freinée par une restriction de substances énergétiques. Ce double impératif n'est guère compatible avec les méthodes classiques d'alimentation qui prévoient la fourniture d'un aliment complet. On peut toutefois pallier la difficulté en distribuant au poussin deux repas séparés de composition différente. Le premier constitue l'apport azoté (protides, vitamines) en quantité restreinte. I e second fournit tous les autres éléments du régime et est alloué ad libitum.

Nous avons montré que le poussin placé dans ces conditions est capable non seulement d'assurer spontanément son besoin énergétique conformément à la loi de HILI et DANSKY (I950), mais encore d'ajuster au mieux sa consommation d'énergie en fonction de la nature des protides alimentaires. En particulier, chez un animal qui reçoit une quantité fixe de protides, l'accès en toute liberté à un régime protéiprive suscite une prise d'énergie qui est associée à l'efficacité azotée de l'ensemble des aliments (ABraham, CALE'T, RÉrat', et Jacquot, I96I). Ainsi, l'un de nous a mis en évidence une corrélation très étroite entre le coefficient d'efficacité protidique des régimes azotés et la consommation spontanée d'énergie (CALE'T, ABRAHAM et Baratou, Ig62). De même, chez le Rat, Rérat, Henry et Jacquót (Ig63) viennent de confirmer nos résultats et établissent une relation entre la quantité đ'azote retenu par l'animal et l'ingestion volontaire de calories.

Dans les cas que nous avons étudiés, la comparaison d'une alimentation mixte ou d'une distribution à part des matières azotées et des substances non azotées montre que la seconde aboutit, par rapport à la première, à des croissances généralement supérieures et chaque fois à des efficacités alimentaires meilleures. Ces remarques ont été mises à profit pour le contrôle de la qualité des aliments azotés (Caleit et Melót, ig6r ; Pereitianu et Abraham, ig63).

On peut néanmoins ne pas être parfaitement convaincu des avantages de cette méthode et lui adresser une critique qui met en cause sa validité : lors de la distribution des repas, l'animal dont la portion protidique est restreinte consomme d'abord l'aliment azoté et ingère ensuite l'aliment non azoté. Il s'ensuit d'une part une discontinuité dans le repas et d'autre part une ingestion des différents principes alimentaires à des moments de la journée plus ou moins éloignés. Or, toute une série de travaux a démontré l'importance de l'ingestion simultanée des éléments nutritifs sur leur destinée. La distribution des vitamines $A_{1} B_{1} C$ et $D$ (MAcko, I956 et MAcko et al., I956) ou d'un acide aminé (GEIGER, I947 ; CANNON et al., I947) ou même simplement de l'eau de boisson (CLEMEN'T, I96I), indépendamment du régime et plusieurs heures après l'ingestion du repas principal, aboutit toujours à une efficacité alimentaire abaissée. Les mêmes observations ont été enregistrées avec des matières azotées complexes. On sait que des protides peu efficaces mais ne possédant pas le même acide aminé comme facteur limitant peuvent être associés avec avantage au sein d'un régime dans la mesure où interviennent les phénomènes de " supplémentation ". Or, HENRy et Kon (I946), GEIGER (I948) et HaRTE et al. (I948) démontrent que les effets heureux de la supplémentation ne se manifestent que si les protides sont présents dans le même aliment et ingérés simultanément. Pour ces auteurs, les protéines tissulaires ne peuvent s'élaborer que dans la mesure où tous les acides aminés constitutifs sont rassemblés au même instant au lieu des synthèses.

Il convient cependant de ne pas conclure hâtivement et de tenir compte de la 
nature des éléments et de l'intervalle de temps qui sépare l'ingestion successive des deux repas. Ainsi, dans le cas de vitamines, MORRISSON et CAMPBELI. (I960), SARETT et MORRISON (I960) et MORRISON et al. (I96I) considèrent que les administrations de $B_{2}$ par sonde stomacale une fois par jour ou incorporée dans l'aliment procurent les mêmes effets de croissance. GEIGER et al. (I949) reconnaissent également que la distribution indépendante de nicotinamide n'a aucune répercussion sur la croissance des animaux ni sur les processus de la synthèse du tryptophane. De même, dans le domaine des acides aminés, Palohermo (I937) et Geiger (I950) estiment que 1'on peut fournir la méthionine, la lysine ou le tryptophane en dehors des heures du repas sans inconvénient pour l'animal dans la mesure où la durée qui sépare les deux ingestions n'excède pas 4 à 5 heures. Enfin, plus récemment, YANG, CIARK et VAIL (I96I), opérant dans des conditions bien précises démontrent que l'apport d'extra-lysine au cours ou après un repas de farine blanche, à des intervalles de temps de $0,4,8$, I2 et I6 heures, provoque les mêmes améliorations sur 1'appétit et sur l'efficacité, la digestibilité et la rétention azotées. Il faut souligner toutefois que la lysine est apportée à la sonde stomacale et non pas incorporée à un repas non azoté. Tout dernièrement, les mêmes auteurs (YANG et al., I963) se placent exactement dans les conditions de GEIGER et distribuent l'extra-1ysine soit dans le repas complet soit en dehors de lui au sein d'un aliment protéiprive. Les mesures de la croissance et de l'azote retenu ne présentent pas de différences significatives selon les deux modes d'administration. Toutefois on remarque un comportement légèrement différent de l'animal lorsque la lysine est apportée $\mathrm{I} 2$ heures après le repas azoté selon que les protides du régime sont constitués de gluten de blé ou de zéine et l'on peut se demander dans quelle mesure l'efficacité d'une alimentation en deux temps ne dépend pas de la nature des constituants du régime.

Les mêmes critiques ont été formulées au sujet de l'alimentation séparée lorsque 1'on distribue les matières azotées d'une part et les aliments ternaires d'autre part. Ainsi GEIGER, BANCROFT et HAGERTY (I950), étudient les aptitudes de restauration protéique chez des rats adultes soumis au jeûne azoté depuis plusieurs jours. Généralement les rats qui reçoivent un régime complet manifestent une aptitude élevée à resynthétiser les tissus protidiques perdus au cours du jeûne. Toutefois cette faculté est surtout marquée lorsque les glucides sont ingérés en même temps que les protides. Lorsque la distribution de ces deux éléments est séparée de plus de 5 heures, la réfection azotée est moins active. Ces résultats ont été interprétés par le rôle d'épargne que manifestent les calories, et mieux les calories glucidiques, au niveau du métabolisme azoté.

A 1'opposé, nos premières expériences semblent montrer que l'animal retire un meilleur profit de l'alimentation séparée que d'une alimentation mixte et complète. Nous nous sommes demandés, si les différences de conditions expérimentales utilisées ne permettaient pas de lever la contradiction entre nos résultats et ceux de GEIGER. Pour rechercher dans quelle mesure la simultanéité de l'apport des substances azotées et non azotées était nécessaire à une bonne efficacité protidique, nous avons comparé la croissance de poussins qui reçoivent des aliments protidiques mélangés ou non à des substances ternaires.

Nous nous sommes également adressés à des matières azotées de deux origines, qui contrastent par la grandeur de leur valeur biologique : farine de poisson dans un cas, tourteaux d'arachide et gluten de maïs dans l'autre. 


\section{MATÉRIEL E'T MÉTHODES}

80 poussins mâles issus de croisement Rhode $\times$ Wyandotte sont répartis à l'âge de 5 semaines en 16 lots homogènes de 5 poussins qui pèsent $35^{\circ} \mathrm{g}$ au moment où débute l'expérience. Chaque facteur est répété 4 fois. (196I)

Les animaux reçoivent les régimes selon le plan de rationnement décrit par CaLET, Melot

Simultanément les poussins ont à leur disposition deux régimes dans des mangeoires séparées. L'une contient l'aliment complémentaire non azoté qui est distribué ad libitum et dont la composition figure dans le tableau I. L'autre renferme le régime protidique qui est alloué en quantité limitée.

TABLEAU I

Composition de l'aliment complémentaire non azoté

\begin{tabular}{|c|c|}
\hline Cérélose.... & 47 \\
\hline Amidon $\ldots \ldots \ldots$ & 40 \\
\hline Cellulose.$\ldots \ldots \ldots \ldots \ldots$. & 2,5 \\
\hline Huile d'Arachide..$\ldots \ldots \ldots \ldots \ldots \ldots$ & 5 \\
\hline Complément Minéral $(1) \ldots$ & 5,5 \\
\hline
\end{tabular}

(1) La composition du complément minéral a été publiée initialement (Calet et Melot, 1961).

Quatre régimes protidiques expérimentaux sont étudiés. Ils diffèrent par la nature des matières azotées (farine de poisson dans un cas, mélange de tourteau d'arachide et de gluten de maïs dans l'autre) et également par le taux protidique ( 50 ou $30 \mathrm{p}$. 100 de matières azotées totales). Les premiers régimes titrant $5^{\circ} \mathrm{p}$. roo de $\mathrm{M}$. A. T. sont dénommés dans le texte par les abréviations « Poisson 50 " et " Arachide 50». Leur composition est donnée dans le tableau 2.

TABLEAU 2

Composition des régimes protidiques contenant 50 p. 100 de matières azotées

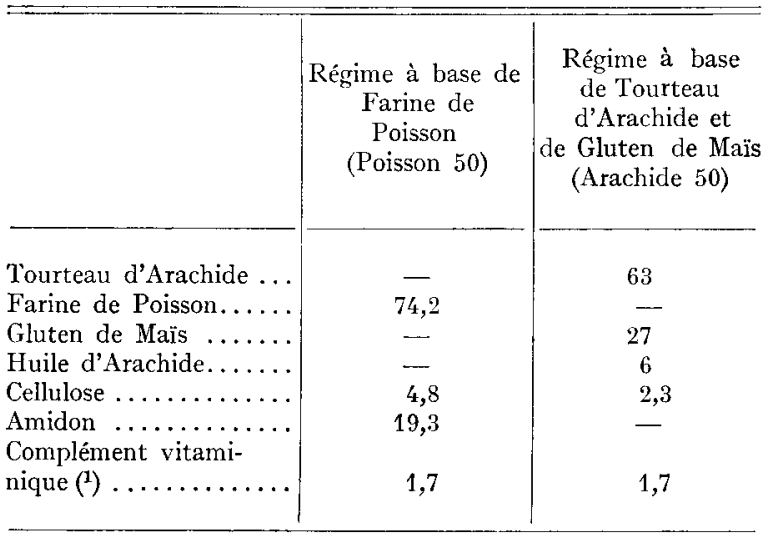

(1) Se référer à l'article de Calet, Melot (1961).

Pour obtenir les régimes protidiques dosant $3 \circ \mathrm{p}$. Ioo de matières azotées totales, on ajoute aux régimes ci-dessus des quantités convenables d'aliment complémentaire non azoté. On abaisse ainsi le taux azoté sans changer l'équilibre des différents constituants protidiques. La composition détaillée de ces derniers régimes figure dans le tableau 3.

Les 4 régimes protidiques sont distribués en quantité limitée de manière à fournir quotidiennement à tous les animaux la même quantité de matières azotées totales. Ces quantités varient d'ailleurs avec l'âge du poussin comme l'indique le tableau 4. 
TABLEAU 3

Composition des régimes protidiques contenant 30 p. Ioo de matières azotées

\begin{tabular}{|c|c|c|}
\hline & $\begin{array}{c}\text { Régime à base de } \\
\text { Farine de } \\
\text { Poisson } \\
\text { (Poisson 30) }\end{array}$ & $\begin{array}{c}\text { Régime à base de } \\
\text { Tourteau } \\
\text { d'Arachide } \\
\text { et de Gluten de } \\
\text { maìs } \\
\text { (Arachide } 30 \text { ) }\end{array}$ \\
\hline Tourteau d'Arachide ... & - & 37,5 \\
\hline Farine de Poisson...... & 44,1 & - \\
\hline Gluten de Maïs ...... & - & 16,1 \\
\hline Huile d'Arachide....... & 2,1 & 5,6 \\
\hline Cellulose ........... & 3,9 & 2,4 \\
\hline Amidon $\ldots \ldots \ldots \ldots$ & 27,7 & 16,2 \\
\hline Cérélose............ & 19,0 & 19,0 \\
\hline Complément Minéral ... & 2,2 & 2,2 \\
\hline Complément Vitaminique & 1,0 & 1,0 \\
\hline
\end{tabular}

TABIEAU 4

Plan de rationnement des animaux (en grammes/jour/poussin)

\begin{tabular}{|c|c|c|c|c|c|c|c|c|}
\hline Age des animaux (semaines) & 6 & 7 & 8 & 9 & 10 & 11 & 12 & 13 \\
\hline Matières azotées totales $(\mathrm{g}) \ldots .$. & 5 & 7 & 9 & 11 & 13 & 15 & 15 & 15 \\
\hline Régimes $(50 \%)(\mathrm{g}) \ldots \ldots \ldots \ldots \ldots$ & 10 & $1 / 1$ & 18 & 22 & 26 & 30 & 30 & 30 \\
\hline Régimes $(30 \%)(\mathrm{g})$. & $1.6,6$ & 23,3 & 30 & 36,6 & 43,3 & 50 & 50 & 50 \\
\hline
\end{tabular}

TABLEAU 5

Teneur des régimes en matières azotées tolales

\begin{tabular}{|c|c|c|c|}
\hline \multirow{2}{*}{ Lots } & \multirow{2}{*}{ Nature des protides } & \multicolumn{2}{|c|}{$\begin{array}{l}\text { Taux de matières } \\
\text { azotées totales }\end{array}$} \\
\hline & & $\begin{array}{l}\text { Prévu } \\
\text { p. } 100\end{array}$ & $\begin{array}{l}\text { Mesuré } \\
\text { p. } 100\end{array}$ \\
\hline Arachide 50 & $\begin{array}{r}\text { Tourteau d'Arachide } \\
\quad+\text { Gluten de mais }\end{array}$ & 50 & 52,2 \\
\hline Arachide 30 & $\begin{array}{r}\text { Tourteau d'Arachide } \\
+ \text { Gluten de maīs }\end{array}$ & 30 & 30,6 \\
\hline Poisson 50 & Farine de Poisson & 50 & 47,6 \\
\hline Poisson 30 & Farine de Poisson & 30 & 30,6 \\
\hline
\end{tabular}


L'analyse des régimes protidiques qui figure au tableau 5 montre que le protocole expérimental que nous venons de présenter n'a pas pu être rigoureusement suivi du fait des écarts entre les valeurs escomptées et les valeurs réelles. Ces dernières ont été les seules retenues dans l'interprétation des résultats.

L'expérience dure 8 semaines (de 5 à I $_{3}$ semaines d'âge) au cours desquelles on effectue un relevé hebdomadaire du poids des animaux et de la consommation de l'aliment complémentaire non azoté. Les animaux sont élevés en batterie, ils sont éclairés artificiellement it heures par jour. Ils disposent d'eau de boisson à volonté.

\section{RÉSULTATS} maines.

Les résultats portent sur l'ensemble de la période expérimentale de 5 à I3 se-

Nous comparons successivement les effets du taux protidique des régimes azotés pour chacun d'entre eux. Le tableau 6 fournit les données relatives au mélange tourteau d'arachide-gluten de maïs.

\section{TABLEAU 6}

Gain de poids, consommation d'aliments et effcacité des régimes à base de tourteau d'arachide et de gluten de maïs

\begin{tabular}{|c|c|c|}
\hline & $\begin{array}{c}\text { Arachide-gluten } \\
50 \%(A \quad 50)\end{array}$ & $\begin{array}{c}\text { Arachide-gluten } \\
30 \% \quad(\mathrm{~A} 30)\end{array}$ \\
\hline Gain de poids (g) & 811 & $884^{4} \quad\left({ }^{2}\right)$ \\
\hline Quantité moyenne de protides distribuée par jour $(\mathrm{g})$. & 11,4 & 11,3 \\
\hline Régime protidique consommé $(\mathrm{g}) \ldots \ldots \ldots \ldots \ldots \ldots$ & 1226 & 2073 \\
\hline Consommation d'aliment complémentaire non azoté (g) & 2089 & 1590 \\
\hline Consommation totale $(g) \ldots \ldots \ldots \ldots \ldots \ldots$ & 3315 & 3663 \\
\hline Indice de consommation $\ldots \ldots \ldots \ldots \ldots \ldots$ & 4,09 & $4,13(1)$ \\
\hline
\end{tabular}

(1) Différence non significative.

(2) Différence significative au seuil de 5 p. 100.

La supériorité du régime A 30 sur le régime A 50 est manifeste, tant en ce qui concerne le gain de poids que la consommation totale d'aliment. A égalité d'apport azoté les taux protidiques faibles améliorent davantage la croissance que ne le font les taux protidiques élevés lorsque l'on s'adresse à des matières azotées de médiocre valeur. La consommation d'aliment complémentaire non azoté est également très différente d'un lot à l'autre. Son interprétation est délicate car elle est conditionnée en partie par la présence plus ou moins grande de substances non azotées dans le régime protidique. Il convient de souligner toutefois que l'indice de consommation demeure inchangé dans les deux types de rationnement. 
Les résultats concernant la farine de poisson sont rassemblés dans le tableau 7 . TABLEAU 7

Gain de poids, consommation d'aliments et effcacité des régimes à base de farine de poisson.

\begin{tabular}{|c|c|c|}
\hline & $\begin{array}{c}\text { Farine de } \\
\text { poisson } \\
50 \% \text { (P 50) }\end{array}$ & $\begin{array}{c}\text { Farine de } \\
\text { poisson } \\
30 \%\left(\mathrm{P}^{3} 30\right)\end{array}$ \\
\hline 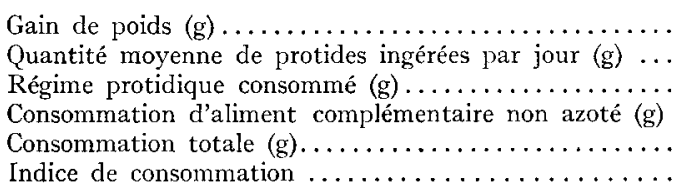 & $\begin{array}{l}1442 \\
\quad 11,1 \\
1300 \\
3364 \\
4664 \\
\quad 3,24\end{array}$ & $\begin{array}{c}1424 \quad(1) \\
11,3 \\
2073 \\
2676 \\
4749 \quad(1) \\
3,34\left({ }^{(1)}\right.\end{array}$ \\
\hline
\end{tabular}

(1) Différence non significative.

Contrairement à ce qui se passe dans le cas du mélange arachide-gluten, le taux protidique du régime azoté ne retentit ni sur la croissance ni sur la consommation totale d'aliment. Il n'exerce pas non plus d'effet sur l'indice de consommation.

L'absence d'effet du taux protéique du régime protidique sur l'efficacité glohale de la ration se manifeste quelle que soit l'origine des matières azotées. Il se manifeste également quel que soit l'âge de l'animal. Le graphique I illustre l'évolution de l'indice de consommation au fur et à mesure que le poulet vieillit.

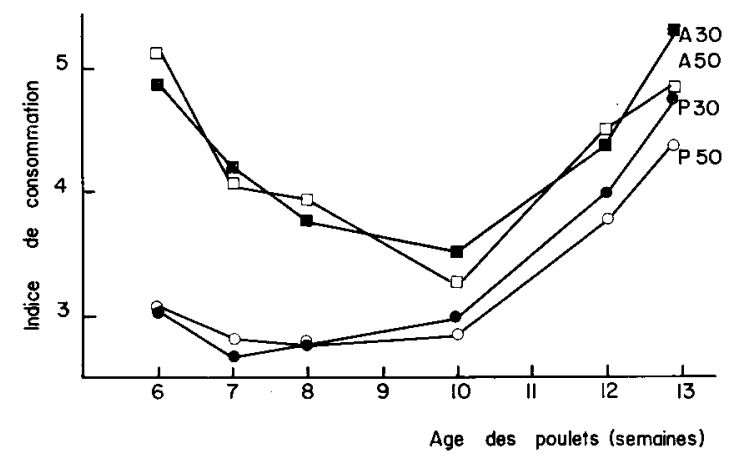

Graphique I. - Évolution de l'indice de consommation des rations en fonction de l'áge du poulet

- Arachide-Gluten $50 \%$

- Arachide-Gluten $30 \%$

- Farine de Poisson $50 \%$

- Farine de Poisson $30 \%$

La valeur de l'indice de consommation est sous la dépendance de la nature de la source azotée : il est d'autant plus avantageux que les matières azotées sont de meilleure valeur biologique. Néanmoins, à aucun moment, il n'est influencé par le plan de rationnement et le taux protidique des régimes. 
On peut étudier d'une manière plus précise la consommation des animaux et estimer rigoureusement la quantité de substances non azotées qu'ils ont ingérée. En effet, la dilution des régimes à $50 \mathrm{p}$. Ioo de matières azotées totales afin d'obtenir des régimes au taux protidique de $30 \mathrm{p}$. Ioo, se traduit par un apport d'une certaine quantité d'aliment complémentaire non azoté que le poulet ingère avec les protides. C'est la raison pour laquelle les consommations d'aliment non azoté qui figurent aux tableaux 6 et 7 n'ont de signification que dans la mesure où l'on compare les régimes ayant même taux protidique. On peut cependant rendre ces valeurs plus facilement interprétables en calculant la quantité de substances non azotées ingérées

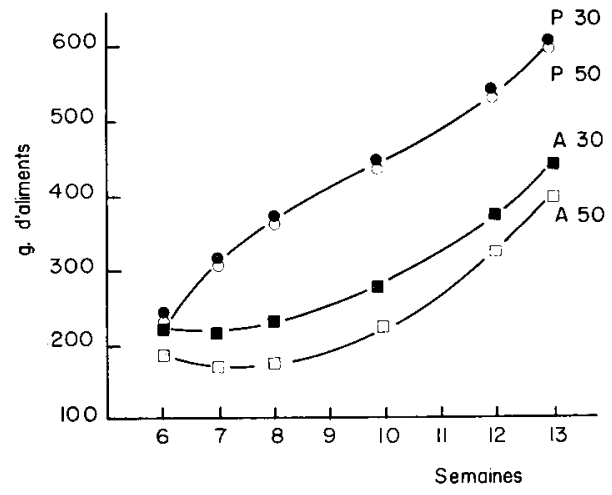

GRAPHIQUE II.

Livolution de la consommation hebdomadaire d'aliment non azoté selon l'áge du poulet

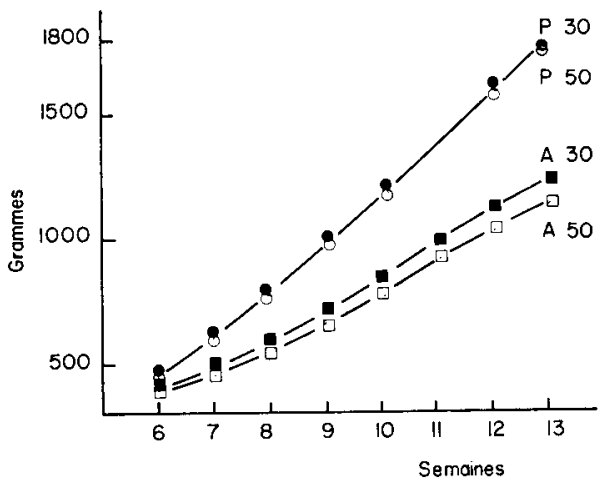

GraphiQue III.

Courbes de croissance

․ Arachide Gluten $50 \%$

- Arachide Gluten $30 \%$

- Farine de Poisson $50 \%$

- Farine de Poisson $30 \%$

avec les régimes à $30 \mathrm{p}$. Ioo de M. A. T. et en 1'ajoutant à la quantité d'aliment complémentaire non azoté librement consommée. Dans ces conditions, les valeurs obtenues sont comparables pour tous les régimes et nous les avons portées sur le graphique II qui traduit les variations de cette consommation avec 1'âge du poulet.

Il apparaît avec une grande netteté que les deux lots recevant de la farine de poisson consomment rigouretısement la même quantité de substances ternaires et ceci à tous les âges de l'animal. Le taux protidique du régime azoté n'intervient en aucune façon. En revanche, les lots nourris du mélange arachide-gluten se comportent différemment. C'est le régime à taux protidique le plus faible qui provoque la consommation d'aliment non azoté la plus élevée. Nous avons fait figurer sur le graphique III les courbes de croissance des animaux et la confrontation des deux graphiques révèle la similitude des deux phénomènes.

En additionnant les quantités consommées sous forme de régime protidique et d'aliment complémentaire on peut reconstituer des régimes complets qui présentent les caractéristiques qui figurent au tableau 8. Nous avons mentionné les rapports entre le gain de poids et la quantité de protides ingérés (coefficient d'efficacité protidique), entre le gain de poids et l'énergie métabolisable ingérée, entre les quantités 
de protides et le poids d'aliment ingéré (taux protidique du régime complet reconstitué), entre les calories et les protides ingérés (rapport $\mathrm{C} / \mathrm{P}$ ).

Le coefficient d'efficacité protidique suit exactement les variations du gain de poids puisque la quantité de matières azotées allouée aux animaux est identique dans tous les cas. Pour la même raison, le taux protidique des aliments que les poulets ont reconstitués varie en sens inverse de la quantité totale d'aliment consommé. A noter toutefois que les protides de haute valeur favorisent la constitution de taux protidiques plus faibles que les protides de valeur médiocre. Il en résulte que les animaux nourris de farine de poisson ont consommé relativement plus d'aliment

TABLEAU 8

Caractéristiques et efficacité des aliments

\begin{tabular}{|c|c|c|c|c|}
\hline \multirow{2}{*}{ Taux protidique } & \multicolumn{2}{|c|}{ Arachide-Gluten } & \multicolumn{2}{|c|}{ Farine de poisson } \\
\hline & $50 \%$ & $30 \%$ & $50 \%$ & $30 \%$ \\
\hline Gain de poids (g) & 811 & 884 & 1442 & 1424 \\
\hline Protides ingérés $(\mathrm{g})$ & 639 & 635 & 620 & $63 \prime$ \\
\hline Coefficient d'efficacité protidique....... & 1,27 & 1,39 & 2,33 & 2,25 \\
\hline Consommation totale d'aliment $(\mathrm{g}) \ldots \ldots$. & 3315 & 3663 & 4664 & 4749 \\
\hline $\begin{array}{l}\text { Taux protéique des régimes complets } \\
\text { reconstitués } \ldots \ldots \ldots \ldots \ldots \ldots \ldots \ldots \ldots \ldots\end{array}$ & 19,3 & 17,3 & 13,3 & 13,4 \\
\hline $\begin{array}{l}\text { Calories métabolisables ingérées } \ldots \ldots \ldots \ldots \\
\text { Gain de poids } \times 1000\end{array}$ & 10968 & 12171 & $156: 8$ & 15967 \\
\hline$\frac{\text { Gain de poids } \times 1000}{\text { calories ingérées }} \ldots \ldots \ldots \ldots$ & 73,9 & 72,6 & 92,1 & 89,2 \\
\hline$\frac{\text { Calories ingérées }}{\text { Protides ingérés }(g)} \ldots \ldots \ldots \ldots \ldots \ldots$ & 17,1 & 19,2 & 25,3 & 25,2 \\
\hline
\end{tabular}

non azoté par rapport aux protides alimentaires que ne l'ont fait les poulets recevant le mélange arachide-gluten. C'est ce que montre les valeurs du rapport Énergie/Matière Azotée.

Les résultats du tableau 8 font également apparaître les variations de l'ingestion totale d'énergie métabolisable en fonction de la nature et du taux azoté des régimes protidiques. Nous retrouvons là encore l'expression du phénomène que nous avons antérieurement signalé : les protides de valeur biologique élevée provoquent une consommation d'énergie accrue lorsqu'on la mesture en valeur absolue mais abaissée si on l'estime en valeur relative par rapport au gain de poids. Ainsi l'utilisation de l'énergie du régime est toujours meilleure lorsque les aliments azotés sont plus efficaces. En revanche, le taux protidique des régimes n'exerce aucune influence sur l'efficacité de l'énergie. Cela est vrai dans le cas de la farine de poisson pour laquelle le taux protidique ne retentit pas sur la consommation d'énergie mais aussi dans le cas d11 mélange arachide-gluten. Une même quantité de protides d'arachide et de gluten offerte dans des régimes à taux protidiques inégaux provoque des gains de poids et des consommations d'énergie différentes en valeurs absolues, mais ces différences s'estompent lorsqu'on les relie l'une à l'autre. Nous avons représenté ce 
phénomène sur le graphique IV qui traduit la relation entre la croissance et la consommation de substances énergétiques à tous les âges de l'animal.

Il apparaît avec une grande netteté que les valeurs correspondant aux quatre régimes étudiés se répartissent sur deux courbes dont les paramètres dépendent de la nature des matières azotées et non pas du taux protidique des régimes. Il convient

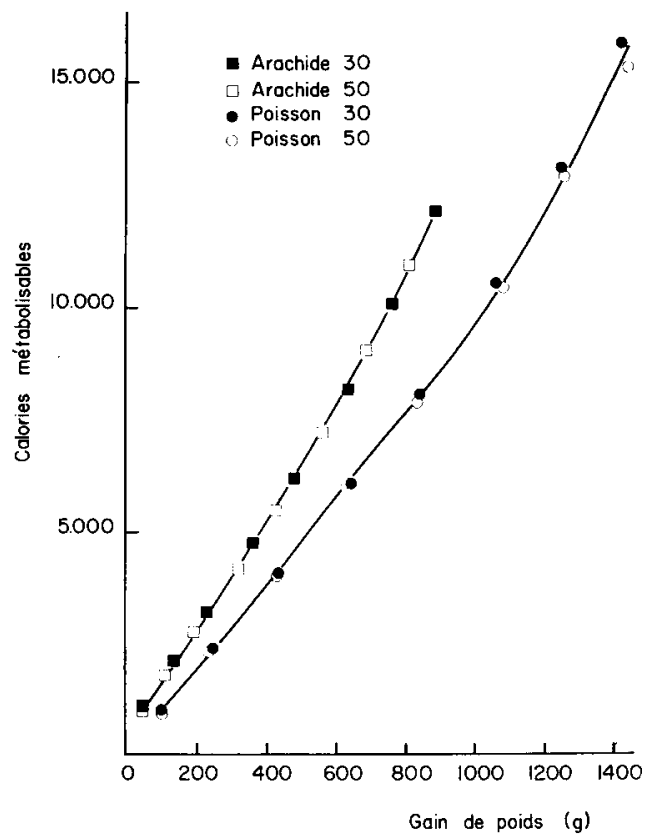

GRAPHIQUE IV. - Relation entre l'évolution du gain de poids et de l'ingestion de calories métabolisables

de souligner que, à tous les moments et pour chaque source protidique, les points se placent rigoureusement sur la même courbe quelles que soient les conditions du rationnement.

\section{DISCUSSION}

De nombreuses études ont bien démontré que le rôle protecteur exercé par l'énergie sur l'utilisation azotée ne se manifeste que dans certaines limites. Au-delà d'une valeur optimum du rapport entre l'énergie et les protides, 1'efficacité azotée des régimes diminue. En revanche peu de travaux ont mis en lumière l'influence de la nature des matières azotées sur cette relation. Les résultats que nous venons de présenter confirment nos précédentes conclusions et montrent une fois de plus la nécessité d'ajuster le taux énergétique du régime selon la valeur biologique de ses protides. L'élévation du taux énergétique peut être bénéfique pour certaines sources d'azote ; elle peut être néfaste pour d'autres. Ceci rejoint les conclusions d'une expérience 
antérieure (CALET, DMAChKIE et BARATOU, I962 (1)) dans laquelle l'enrichissement $\mathrm{du}$ régime en énergie permet de valoriser la farine de poisson. En revanche, il ne modifie pas l'efficacité du tourteau de soja, protide de valeur moyenne et est nuisible au tourteau d'arachide, protide de qualité médiocre. Dans le même ordre d'idées, Saxena, Jensen et MacGinnis (I96I), démontrent que le poussin ne retire aucun avantage de l'incorporation de matières grasses au régime lorsque ses protides sont constitués de soja cru.

La confrontation de nos résultats présents et de ceux obtenus précédemment (CAIET, JOUANDET et BARATOU, I96r) fait ressortir la similitude des valeurs du rapport Calorie/Matière Azotée observées dans les deux cas. Ainsi avec les mêmes régimes des animaux jeunes ( 4 semaines) ou des poulets plus âgés (5 à I 3 semaines) ingèrent des quantités égales de calories par rapport aux protides. La signification de la constance du rapport Calorie/Matière Azotée selon l'âge est discutée dans une note annexe (CAIET et ALBESSARD, I963 $\left(^{1}\right)$ ).

D'autres conditions seraient également nécessaires pour observer le rôle protecteur de l'énergie glucidique sur l'utilisation azotée. D'après GEIGER et ses disciples, cet effet ne peut se manifester pleinement que si les aliments azotés et non azotés sont ingérés simultanément. Il convient toutefois de ne pas incriminer a priori tout autre mode de rationnement. Nous pouvons à titre de comparaison indiquer les valeurs de gains de poids obtenus généralement par des animaux de même souche, élévés dans les mêmes conditions et nourris ad libitum avec un aliment standard parfaitement équilibré, dosant $20 \mathrm{p}$. Ioo de matières azotées et répondant aux normes classiques du poulet de chair. Les poulets gagnent au cours de la ro semaine $\mathrm{I} 8 \mathrm{o} \mathrm{g}$ de poids et consomment $770 \mathrm{~g}$ d'aliment. Ce faisant, ils ingèrent en moyenne $22 \mathrm{~g}$ de matières azotées par jour. Dans les mêmes conditions, nos animaux expérimentaux nourris de farine de poisson reçoivent quotidiennement $9 \mathrm{~g}$ seulement de matières azotées et leur gain de poids hebdomadaire est de $2 \mathrm{I} 4 \mathrm{~g}$ au même âge. Cette comparaison n'est pas rigoureuse puisque les aliments azotés confrontés ne procèdent pas de la même origine; les différences observées sont toutefois suffisamment importantes au profit de l'alimentation séparée pour qu'on ne puisse pas la rejeter sans discussion.

Nous avons précédemment décrit l'expérience de GEIGER, BANCrOFT et HAGERTY (I950) qui étudient la réfection azotée de rats préalablement carencés et qui reçoivent la même quantité d'azote soit en mélange avec le repas glucidique soit séparée de lui par un intervalle de temps supérieur à 5 heures. De même GEIGER, E, RAwr et Thomas (I955) aboutissent aux mêmes conclusions en nourrissant des rats pendant 32 jours avec des quantités limitées d'azote, soit en leur donnant des régimes complets, soit en distribuant les fractions azotées et glucidiques à des moments de la journée éloignés de I 2 heures. Dans tous les cas observés, la séparation dans le temps des deux types de repas entraîne soit un arrêt de la croissance soit un bilan azoté négatif.

Ces conclusions ne sont pas acceptées par tous les auteurs. Chez l'Homme, d'une part Volkmann (I947) et GERNAND (I95 I), et chez le Rat d'autre part HarTe et TraVERS et SARICH (I948), n'observent aucune différence d'efficacité du régime selon le

(1) Résultats non publiés. 
mode de rationnement à la condition d'avoir préalablement habitué le sujet à consommer la substance azotée qu'ils étudient.

Les conclusions de GEIGER semblent s'opposer également aux nôtres (CALET JoUANDET et BARATOU, rg6r) lorsque nous affirmons que l'animal retire un meilleur bénéfice d'une même quantité de farine de poisson lorsquelle est distribuée en dehors d'un repas protéiprive.

Pour expliquer ces contradictions il ne faut pas oublier que GEIGER compare des animaux qui reçoivent la même quantité d'énergie. Or, l'énergie allouée par jour dans ses expériences, est manifestement insuffisante. Il en résulte, surtout avec les régimes à taux protidique élevé, qu'une fraction de l'azote est utilisée à des fins énergétiques, ce qui réduit d'autant la part des protides utilisés à des fins azotées. Dans nos essais, au contraire, les poussins satisfont à leur convenance leur besoin énergétique au moyen de l'aliment ternaire qu'ils ingèrent séparément. Il en résulte vraisemblablement, comme l'ont montré MAT'TERSON et al. (I958), une mauvaise utilisation énergétique de la ration mais en contrepartie une meilleure utilisation azotée. Cette conception est d'ailleurs renforcée par les résultats de GEIGER lui-même lorsqu'il donne à discrétion les deux types de repas. Dans ces conditions, l'animal ne peut consommer simultanément l'ensemble des éléments nutritifs mais il peut couvrir ses besoins énergétiques. On n'observe pas alors de réduction du coefficient d'efficacité protidique du régime.

Les raisons qui ont divisé les auteurs peuvent être plus subtiles. Ainsi MIUrro et Wikramanayake (I954) reproduisent les expériences de GerGER et nuancent ses conclusions. Ils enregistrent le premier jour de l'essai une excrétion urinaire d'azote plus importante lorsque le repas glucidique est séparé de I 2 heures du repas azoté. Toutefois, le phénomène ne se maintient pas : au bout de deux jours, l'animal profite du repas glucidique de la veille et l'effet d'épargne des glucides vis-à-vis de l'azote se manifeste à nouveau avec la même intensité. I’affaiblissement passager du bilan azoté de l'animal nourri de deux repas séparés traduit son manque d'adaptation au nouveau mode de rationnement.

On peut penser également que le mode de distribution du repas n'est peut-être pas le seul facteur en cause. Il y a lieu de considérer la composition des régimes utilisés. Ainsi, Marfatia et Sreenivasan (I960) montrent que les résultats du mode de distribution des aliments est en particulier tributaire de leur richesse en vitamines $B$. La scission des fractions glucidique et azotée est néfaste si le régime est appauvri en vitamines hydrosolubles. Aucune différence en revanche ne se manifeste, lorsque les régimes sont enrichis de toutes les vitamines du groupe $B$.

De la même manière, nos résultats actuels attirent l'attention sur le rôle joué par la nature des matières azotées. Dans nos essais, le dédoublement des repas et l'absence de substances ternaires ajoutées au repas azoté n'ont aucune action contraire ni sur la croissance, ni sur l'efficacité azotée du régime, lorsque les protides sont représentés par la farine de poisson, alors qu'elle se'manifeste par une réduction du gain de poids lorsque l'on s'adresse au tourteau d'arachide. Parmi les différences qui existent entre ces deux sources azotées, on peut mentionner la répartition de leurs acides aminés qui détermine la valeur biologique, la disponibilité de ces acides aminés qui conditionne leur vitesse de libération dans l'intestin et leur digestibilité, et enfin la présence de glucides dans le second et non dans le premier.

D’après GEIGER, la farine de poisson aurait dû souffrir le plus du mode de ration- 
nement employé. Pour être utilisée au mieux, elle requiert une plus grande quantité de substances énergétiques que le mélange arachide-gluten dont la valeur biologique est moindre.

D'après Thomson et MunRo (I955), les protides devraient retirer un plus grand bénéfice de l'association avecles sucres, lorsque le régime protidique renferme $30 \mathrm{p}$. Ioo de matières azotées, que lorsqu'il en possède $50 \mathrm{p}$. Ioo. Or cela se confirme bien dans le cas de l'arachide, et non pas avec la farine de poisson.

Dans nos expériences antérieures toute amélioration de l'efficacité azotée du régime s'accompagne d'un abaissement de l'indice de consommation et d'une meilleure utilisation de l'énergie. Ceci apparaît d'ailleurs sur les graphiques I et IV lorsque l'on compare les rations à base de farine de poisson à celles renfermant le tourteau d'arachide et le gluten de maïs. A l'opposé, des régimes de constitution différente mais possédant les mêmes protides ont des indices de consommation et des efficacités énergétiques rigoureusement égaux. Ainsi, la présence ou l'absence de substances non azotées dans l'aliment protidique n'affecte en rien l'efficacité globale de 1'aliment.

Le comportement opposé que nous avons relevé entre les deux sources azotées étudiées (arachide-gluten d'une part et farine de poisson de l'autre) ne se manifeste que dans la mesure où l'on choisit le gain de poids comme critère d'efficacité. Il disparaît lorsque l'on s'adresse à l'indice de consommation ou mieux encore à l'efficacité calorique. Dans ce dernier cas, le graphique IV illustre d'une manière saisissante la relation qui unit la consommation spontanée d'énergie au gain de poids. La manière dont les deux paramètres sont liés dépend essentiellement de la nature des protides du régime mais non pas de la façon dont ils sont distribués.

Il résulte de ces observations que le plan de rationnement et le mode de distribution des protides du régime retentissent parfois sur la croissance de l'animal mais jamais sur le taux de conversion alimentaire. Ils affectent parfois la consommation d'énergie, mais jamais son utilisation.

Dans ces conditions, le mode de distribution des protides - lorsqu'il influence la croissance - manifeste ses effets essentiellement par le relai des ingérés énergétiques. On peut se demander dès lors par quel mécanisme des quantités de matières azotées identiques distribuées dans des régimes à taux protidique variable, interviennent sur l'appétit de l'animal et pourquoi le phénomène se manifeste avec certain type d'aliment et non pas avec d'autres.

Reçu pour publication en juin 1963 .

\section{SUMMARY}

EFFECT OF SEPARATE FEEDING ON THE EFFICIENCY OF THE DIET AND THE NUTRITIONAL BEHAVIOUR OF CHICKEN

Between the years I946 and 1950, GEIGER and other workers (HENRY, Kon, I946; HARTE and $a l$., 1948), found that the protein fraction of the diet had to be given within 5 hours after the rest of the meal for a good protein utilization.

In a 8-week experiment, protein and the protein-free parts of the diet were given separately : fish meal or peanut oil meal-corn gluten, mixed with minerals and vitamins, were used as protein 
meals and were given either alone (50 p. roo crude protein level for this protein fraction) or mixed up with some of the protein-free fraction, in order to obtain a $30 \mathrm{p}$. 100 protein level diet. According to GEIGER, ternary ingredients given with proteins, owe to improve their utilization. All the protein parts were provided in restricted amount so that all the animals received the same quantity of proteins. (The experimental procedure is shown in tables 4 and 5). The protein-free part was given ad libitum.

Weight gain, feed intake, protein efficiency (PER) were found to be strictly the same when fish meal was used, irrespective of the protein level of the protein part of the diet. On the contrary, for the peanut-gluten diet, weight gain and PER depended on the protein level of the protein part: when nitrogen were equalized, feed intake - and consequently growth - were better with the $30 \mathrm{p}$. 100 protein part than with the $50 \mathrm{p}$. 100 one. However, there were no difference in feed efficiency.

These results are in agreement with those of GEIGER only when low quality proteins are used (peanut-gluten) and not with higher quality proteins (fish meal).

It appears (figures 2,3) that the difference between the two protein levels of the protein meal is owing, in the major part, to differences in calorie intake. And it might be asked whether this higher weight gain is not due to a higher intake, since, when weight gains are plotted against calorie intake (figure 4), the different diets are expressed by two curves which essentially depend on the kind of protein ; neither the protein level of the nitrogen part. nor its mode of administration has any influence on this results. Low quality proteins give better chick growth when they are given with protein-free diet. This improvement does not occur with fish meal and in any way, it disappears when total diet efficiency is concerned.

As delaved nutrition modifies only feed intake, and not feed utilization, it remains to determine why chicks eat spontaneously more calories when they are given, apart from the diet, a 30 p. Ioo low quality protein fraction than when they are given a $5^{\circ} \mathrm{p}$. Ioo low quality protein fraction.

\section{RÉFÉRENCES BIBLIOGRAPHIQUES}

Airaitay J., Chlet C., Rerat A., Jacquot R., 1961. Solidarité des besoins énergétique et protéique de croissance : L'ajustement spontané des calories et des protides. C. R. Acad. Sci., 253, 27682770 .

Anwar A., ig62. Estimation of gross protein value : 2. In proteins of plant origin. Poult. Sci., 41, ro23-1026.

BARnes R. H., Bosshardt D. K., 19+6. The evaluation of protein quality in normal animal. Ann. N. Y. Acal. Sci., 47, 279 .

Calet C., Jouandet C., Baratou J., i96r. Variation de la consommation spontanée d'énergie du poussin en fonction de la nature des matières azotées du régime. 1 nn. Biol. anim. Bioch. Biophys., 1, 5-9.

Calet C., Melot M., rg6r. Efficacité comparée pour la croissance du poussin de la méthionine et du sel de calcium de l'acide hydroxyméthylthiobutyrique (M. H. A.). Ann. Zootech., 10, 205-213.

Calet C., Abrailan F., Baratou J., ig62. Influence de la valeur biologique des protides du régime sur la consommation spontanée d'énergie du poussin. XIIth World's Poultry Congress, Proceedings Section papers. 208-2 I I, Sydney, Australia.

Cannon P. R., Steffee C. H., Frazier L. J., Rowley D. A., Stepto R. C., i947. The influence of time of ingestion of essential amino acids upon utilization in tissue synthesis (abstr.). Fed. Proc., 6, 390.

Clement G., 1961. Modifications pondérales observées au cours de la croissance chez le rat lorsque l'eau de boisson et la nourriture solide sont octroyées à des temps différents. Rev. Canad. Biol., 20, 769-772.

Comrs G. F., 1959. Maryland Conference focuses attention on recent findings in poultry, animal feeding. Feedstuffs, 31 (12), $5^{2-56}$.

Geiger E., I947. Experiments with delayed supplementation of incomplete amino acid mixtures. J. Nutr., 34, $97^{-\mathrm{I} I \mathrm{I}}$.

GeIGER E., I948. The role of the time factor in feeding supplementary proteins. J. Nutr., 36, 813-819.

Geiger E., Hagerty F. B., Gatchell H. D., 1949. Transformation of tryptophan to nicotinic acid investigated with delayed supplementation of trypiophan. Arch. Biochem., 23, 315-320.

GEIGER E., 1950. The role of the time factor in protein synthesis. Science, 111, 594-599.

Geiger E., Baicroft R. W., Hagerty E. B., I950. The nitrogen sparing effect of dietary carbohydrate in its relation to the time factor. Experiments with repletion of protein-depleted adult rats. $J$. Nutr., 42, $577-585$.

Geiger E., El Rawi I., Thomas H. V., 1955. Experiments with intermittent feeding of protein to rats. J. Nutr., 56, 373-374.

Gernand K., r951. Stossweise Fatt-Eiweisszufuhr bei gleichzeitiger calorischer Unterernährung. Klin. Wschr., 30, r99. 
Guillaume J., Ig6r. Les facteurs de variation du rapport calories/matières azotées totales dans les régimes du poussin. Ann. Zootech., 10, 279-3I I.

Harte R. A., Travers J. J., Sarich P., I948. The effect on rat growth of alternated protein intakes. J. Nutr., 35, 287-293.

Heiman V., Carver J. S., Cook J. W., I939. A method for determining the gross value of protein concentrates. Poult. Sci., 18, 464-474.

Henry K. M., Kon S. K., I 946 . The supplementary relationships between the proteins of dairy products and those of bread and potato as affected by the method of feeding with a note on the value of soybean protein. J. Dairy Res., 14, 330-339.

Hill F. W., Dansky L. M., i95o. Studies on the protein requirements of chicks and its relation to dietary energy level (abstr.). Poult. Sci., 29, 763.

Hohls H. W., I958. Der Einfluss des Kalorieneiweissverhältnisses auf die Rohverwertung bei wachsenden Hühnern. Arch. Geflïcgelk., 22, 395-415.

Leong K. C., Sunde H. L., Bird H. R., Elvehjem C. A., 1959. Interrelationships among dietary energy, protein and amino acids for chickens. Poult. Sci., 38, т267-I 285.

Macko S. N., 1956. Vitamin requirement when introduced periodically (en russe). Izv. Akad. Nank. S.S.S.R. Ser. Biol, 4, 102-I 55 (in Nutr. Abstr. Rez., 2\%, 1657).

Macko S. N., Gorbunova V. I., Zmeido A. T., 1956. The requirement for vitamin C during its periodic intakes (en russe). Bjull. Eksp. Biol. Med., 1, 22-26 (in Nutr. Abstr. Rev., 2\%, 421).

Marfatia U., Sreenivasan A., I960. Effects of marginal and optimal intakes of B vitamins on proteinutilization by the growing rat from varied dietaries. $J$. Nutr., 70, $156-162$.

Matterson L. B., l'oter L. M., Arnold A. W., Singsen E. P., i 958. Studies in evaluating energy content of feeds for the chick. 2. Methods of evaluating feed ingredients for their metabolizable energy in the chick (abstr.). Poult. Sci., 37, 1225.

Morrison A. B., Campbell J. A., I960. Vitamin absorption studies. I. Factors influencing the excretion of oral test doses of thiamine and riboflavine by human subjects. $J$. Nutr., $7 \mathbf{2}, 435-440$.

Morrison A. B., Middreton E. J., Campbel. J. A., ig6r. The utilization of riboflavin given periodically to the rat apart from the diet. Canad. J. Biochem. Physiol., 39, I 543-1550.

Munro H. N., Wikramanayake T. W., I 954 . Absence of a time factor in the relationship between level of energy intake and protein metabolism. J. Nutr., 52, 99-I I4.

Paloheimo L., I937. Ủber die Ėrgängzung von Casein durch Verabreichung von l-cystin. Biochem. Z., 295, 48-57.

Peretianu J., Abraham J., ig63. Nouvelles techniques de mesure du coefficient d'efficacité protéique. Ann. Nutr., 17, 8I-IO2.

Rerat A., Henry Y., JacQuot R., ig63. Relation entre la consommation spontanée d'énergie et la rétention azotée chez le rat en croissance. C. R. Acad. Sci., 256, $787-789$.

Sarett H. P., Morrison A. B., ig6o. 'The utilization of some B vitamins administrated to the rat apart from the diet. J. Nutr., 70, 37-4I.

Saxena H. C., Jensen L. S., McGinnis J., ig6r. Growth inhibition by raw soybean meal for chicks and turkey poults. Poult. Sci., 40, I452-I 453 .

Thompson W. S. T., Munro H. N., I955. The relationship of carbohydrate metabolism to protein metabolism IV. The effect of substituting fat for dietary carbohydrate. J. Nutr., 56, I 39-150.

VolkmanN I947. Letter to the editor. Disch. Gesundheitswes., 17, 545.

YANG S. P., ClaRK H. E., VAIL G. E., I96I. Effects on varied levels and a single daily supplement of lysine on the nutritional improvement of wheat flour proteins. J. Nutr., 75, 24I-246.

Yang S. P., Steinhader J. E., Masterson J. E., ig63. Utilization of a delayed lysine supplement by young rats. 7. Nutr., $79,257^{-26 r}$. 